\title{
Çocukluk Çağı Obezitesinde Fizyoterapi ve Rehabilitasyon
}

\section{Physiotherapy and Rehabilitation in Childhood Obesity: Review}

\author{
Pınar Yaşar ${ }^{1 *}$, Zeliha Başkurt ${ }^{1}$ \\ ${ }^{1}$ Süleyman Demirel Üniversitesi, Sağlık Bilimleri Fakültesi, Fizyoterapi ve Rehabilitasyon Bölümü, \\ Isparta/Türkiye.
}

Email: pinarergoz@gmail.com; zelihabaskurt@sdu.edu.tr. ORCID: 0000-0002-6671-0238

ORCID: 0000-0001-7488-9242

*Sorumlu yazar/ Corresponding Author: Pınar Yaşar

Gönderim Tarihi / Received: 27.05.2021

Kabul Tarihi / Accepted: 05.07.2021

DOI: $10.34087 /$ cbusbed.943441

\begin{abstract}
Öz
Çocukluk çağı obezitesi, beslenme değişiklikleri ve fiziksel inaktiviteye bağlı olarak ortaya çıkan, prevalansı gittikçe artan ciddi bir problemdir. Çocukluk çağında obezitenin neden olduğu kardiyorespiratuar ve metabolik hastalıklar yetişkinlik dönemi için de büyük tehlike oluşturmaktadır. Çocuklarda fiziksel aktivitenin azalmasıyla, aşırı kilo veya obezite ihtimali daha da artmaktadır. Fiziksel aktivitenin sürdürülmesi, doğru beslenme ve uykunun düzenlenmesi ile çocukluk çağı obezitesine yönelik koruyucu rehabilitasyon sağlanmaktadır. Doğru beslenme için, besin değeri düşük, yüksek kalorili yiyecekler yerine sebze ve meyve gibi lifli gıdaların tercih edilmesi gerekmektedir. Çocuklarda kaliteli uyku beden kitle indeksinin korunması ve obezitenin önlenmesinde büyük bir yardımcıdır. Düzenli fiziksel aktivitenin çocuklarda kemik gelişimi ve kilo kontrolünü sağladığı bilinmektedir. Çocukluk çağında yapılan düzenli egzersiz vücut kompozisyonun geliştirilmesi ve kardiyometabolik sağlığın sürdürülmesini sağlamaktadır. Çocuklara egzersiz alışkanlığının kazandırılması ve okulda yapılabilecek çeşitli egzersizlerle fiziksel aktivitenin artırılması hedeflenmektedir. Bu derlemenin amacı çocuklar için önerilebilecek alternatif egzersizler olan aerobik egzersizler, pilates, yoga, yüksek yoğunluklu aralıklı antrenman (HIIT) ve sanal gerçeklik uygulamalarını incelemektir.
\end{abstract}

Anahtar kelimeler: Çocukluk çağı obezitesi, Egzersiz, Rehabilitasyon.

\section{Abstract}

Childhood obesity is a serious problem with increasing prevalence due to dietary changes and physical inactivity. Cardiorespiratory and metabolic diseases caused by childhood obesity also pose a great danger for adulthood. With the decrease in physical activity in children, the possibility of overweight or obesity increases even more. Preventive rehabilitation is provided for childhood obesity by maintaining physical activity, proper nutrition and sleep regulation. For proper nutrition, foods with fiber such as vegetables and fruits should be preferred instead of highcalorie foods with low nutritional value. Quality sleep in children is a great helpful in maintaining body mass index and preventing obesity. It is known that regular physical activity provides bone development and weight control in children. Regular exercise in childhood provides improvement of body composition and maintenance of cardiometabolic health. It is aimed to get children adopt the exercise habit and to increase physical activity with various exercises that can be done at school. The purpose of this review is to examine the alternative exercises that can be recommended for children, such as aerobic exercises, pilates, yoga, high intensity interval training (HIIT) and virtual reality.

Keywords: Childhood obesity, Exercise, Rehabilitation. 


\section{Giriş}

Küresel bir salgın haline geldiği bilinen obezite, Dünya Sağlık Örgütü (DSÖ) tarafından "bireyin sağlığına zararlı olacak şekilde anormal veya aşırı yağ birikimi” şeklinde tanımlanır[1]. Gelişmiş ve gelişmekte olan ülkelerde önemli bir halk sağlığ sorunu olarak kabul edilir[2]. Çocukluk çağı obezitesi ise dünya genelinde prevelansı gittikçe artan büyük bir problemdir[3]. DSÖ tarafından Avrupa Bölgesi'nde çocukların ve yetişkinlerin yaklaşık \%20'sinin fazla kilolu ve üçte birinin obez olduğu belirtilmektedir[2]. Çocukluk çağında görülen obezitenin çok az bir kısmı (\%1-2) hastalık veya herhangi bir sendrom nedeniyle oluşmaktadır ve kalan büyük çoğunluk ekzojen obezite olarak adlandırılmaktadır[4]. Eksojen obezite, altta yatan herhangi bir hastalık olmadan görülen obezite tipidir. Alınan kalori ile harcanan enerji arasındaki dengesizlik ile ortaya çıkar. Etyolojisinde genetik, yaş, cinsiyet, fiziksel aktivite düzeyi, beslenme alışkanlıkları ve sosyoekonomik kültürel düzey sayılabilir[5].

Obezite, beslenme değişiklikleri ve fiziksel inaktiviteye bağlı olarak günümüzün en yaygın hastalığ 1 haline gelmiştir. Çocukluk çağı obezitesinin neden olduğu kas iskelet sistemi problemleri, kardiyorespiratuar ve metabolik rahatsızlılar yetişkinlik dönemi için de büyük tehlike oluşturmaktadır. $\mathrm{Bu}$ durumun önüne ancak doğru beslenme teknikleri ve egzersizle geçilebilir[6].

\section{Obezitenin değerlendirilmesi}

Obezitenin belirlenmesinde kullanılan çok sayıda direkt ve indirekt yöntem vardır. Direkt yöntemler vücut dansitesinin hesaplanması, impedans ölçümü, vücut elektriksel geçirgenliği gibi yöntemlerdir. İndirekt yöntemlerde ise antropometrik ölçümler kullanılmaktadır. Bunlar; beden kütle indeksi, boya göre ağırlık oranı, yaşa göre vücut ağırlığı, deri kıvrımı ölçümleri, bel/kalça oranı, üst kol çevresi ölçümüdür[7,8]. Direkt yöntemler pahalı ve ulaşılması zor olduğu için klinikte daha çok indirekt yöntemler tercih edilir ve sıklıkla "Beden Kütle İndeksi (BKI)" kullanılır. Vücut ağırlığı ve boy hesaplaması ile elde edilen BKİ, 2 yaş ve üzeri çocuklarda aşırı kilo ve obezite için kullanılan klinik standart bir ölçümdür. Bel çevresinin kalça genişliğine oranı abdominal obeziteyi değerlendirirken kullanılabilir, deri kıvrım kalınlığı da yağ dokusunun ölçülmesinde yardımcı olabilir[9]. İdeal ağırlık hesaplaması, çocuğun kilosunu yaş ve cinsiyete göre yapılmış standart tablolar üzerinde değerlendirmekle mümkün olmaktadır. Çocuğun boyuna göre kilosu 90-95 persentilin üzerindeyse aşırı kilolu/ obez olarak kabul edilmektedir[8].

Çocuklar için yapılan fiziksel uygunluk ölçümleri, çocukların bedenlerine yönelik olumlu tutum geliştirmelerini sağlarken, fiziksel durumları hakkında bilgi edinmelerine de yardımcı olur. El kavrama kuvveti, dikey sıçrama, otur-uzan testi, mekik çekme, barfiks ve flamingo denge testi gibi değerlendirmelerin yer aldığı EUROFIT testlerinden mekik ve flamingo denge testi adolesan obezitesinin değerlendirilmesinde oldukça önemlidir[10].

Çocukluk çağı obezitesi sadece endokrin, gastrointestinal, muskuloskeletal, pulmoner ve kardiyovasküler sistem için değil vücuttaki hemen her sistemi olumsuz etkileyen komorbiditeler ile ilişkilidir[9]. Önceki yıllarda yetişkin hastalıkları olarak bilinen Tip 2 diyabet, obstrüktif uyku apnesi, dislipidemi gibi obezite ile ilişkili hastalıklarla çocukluk döneminde artık daha s1k karşılaşılmaktadır[6,11,12]. Aşırı kilo ve obeziteye bağlı oluşan biyomekaniksel değişiklikler özellikle çocukluk çağında kas iskelet sistemi ve eklemlere fazla yük binmesine neden olmaktadır. Kiloya uyum sağlamak için yürüyüş paternlerinin değişmesi, yüklenmeye bağlı olarak femur başındaki büyüme plaklarının eksternale dönmesi gibi durumlar eklemlerde kalıcı biyomekaniksel sorunlar oluşturmaktadır[13].

Çocukluk döneminde obezite riski taşıyanların yetişkin dönemde de aşırı kilolu veya obez olma ihtimalinin yüksek olduğu bilinmektedir[11,14]. Çocukluk çağı obezitesi yetişkinlik döneminde sadece kilo durumunu etkilemekle kalmayıp farklı kronik rahatsızlıklara da zemin oluşturmaktadır. Obezitenin kardiyovasküler hastalıklar, tip 2 diyabet, kronik böbrek rahatsızlığ 1 , kanser gibi hastalıklarla yakından ilişkili olduğu gösterilmiş, yaşam süresinin kısalması ve ölüm riskinde artışa neden olduğu bildirilmiştir[15].

\section{Beslenme}

Çocukluk çağında beslenmenin düzenli olması obezite oluşumunu engelleyen önemli bir faktördür. Yapılan bazı çalışmalarda özellikle kahvaltı öğününün atlanmasının obeziteye yatkınlığı artırdığı sonucuna varılmıştır[11]. Okul çocukları ve özellikle adolesanların ev dışı yiyecek ve içecek seçimlerinde daha serbest olmaları besin değeri düşük, daha yağlı, şekerli yiyecek ve meşrubatları tercih etmelerine olanak tanımaktadır. Çocuklarda sebze ve meyve tüketiminin artırılmasının obeziteyi önlediği, lifli g1dalar ve yeteri miktarda süt tüketiminin obeziteye karşı koruyucu etkisi olduğu bilinmektedir[6].

Çocukluk çağı beslenme önerileri sıralanacak olursa; en az beş porsiyon sebze ve meyve tüketimi, doymuş yağ içeren, tuzlu atıştırmalıklar, şekerli yiyecekler gibi kalorili gıdaların azaltılması, şeker içeren içecek alımını en aza indirmek, ev dışında yemek ve özellikle ayak üstü yiyecekleri en aza indirmek, kahvaltı yapmak ve öğün atlamamak şeklinde S1ralanabilir[4,9].

\section{Uyku alışkanlığı}

Yeterli miktardan daha az uyuyan çocuklarda obez olma olasılığının daha yüksek olduğu, uyku alışkanlığının obezite ve mortalite ile ilişkili olduğu bildirilmiştir[16]. Hem yetişkinlerde hem de çocuklarda yetersiz uykunun ruh hali ve bilişsel işlev üzerindeki olumsuz etkilerine ek olarak uyku ile obezite arasında bir ilişki olduğu gösterilmiştir[17]. Çocukların kalite ve süre açısından uykularının zayıf 
olması, kilolu olmaları ile ilişkilendirilmiştir[6]. Literatür incelendiğinde, bir derleme çalışmasında uyku süresine bakılmadan kalitesiz uykuya sahip çocuklarda BKI'nin daha yüksek olduğu, başka bir çalışmada ise uyku süresi ile BKİ ve bel çevresi arasında ters orantı olduğu bulunmuştur[18].

\section{Fiziksel aktivite}

Fiziksel aktivite, bebekler ve çocukların sağlıklı büyümesi ve gelişmesi için oldukça gereklidir[19] Çocukluk çağı obezitesini yönetmede oldukça önemli bir bileşendir[20]. Düzenli fiziksel aktivitenin 3-17 yaş aralığındaki çocuklarda kemik gelişimi ve kilo durumunu geliştirdiği, 6-17 yaş aralığında kardiyorespiratuar ve kas zindeliğine, kardiyometabolik sağlığa katkı sağladığı, 6-13 yaşları arasında bilişsel fonksiyonları iyileştirdiği ve depresyon riskini azalttığ 1 söylenmektedir[19].

\subsection{Egzersizin önemi}

Çocukluk çağı obezitesi yönetiminde egzersiz vücut kompozisyonunun geliştirilmesi, kardiyometabolik sağlığın sürdürülmesi açısından oldukça önemli bir komponenttir[21]. Dünya Sağl1k Örgütü (DSÖ) tarafından yayınlanan kılavuzda, 5-17 yaş aralığındaki çocukların, günde en az $60 \mathrm{dk}$ orta veya şiddetli düzeyde, aerobik tipte fiziksel aktivite yapması önerilmektedir[22]. Çocuklar ve gençler doğal gelişimlerini destekleyen, keyifli ve güvenli çeşitli fiziksel aktivitelere katılmaya teşvik edilmelidirler. Haftada 2-3 kez yapılan ağaca tırmanma, çekme-itme oyunları, koşma, dönme veya zıplama gibi aktiviteler çocukların kas gücüne katkıda bulunurken kardiyorespiratuar fonksiyonlarını da iyileştirmektedir[22].

Çocuklara obeziteyi önlemeye yönelik önerilebilecek oyun dıșı egzersiz çeşitleri gruplandırılacak olursa;

Aerobik egzersizler: Koşu, bisiklete binme, dans, takım sporları, yüzme, tenis, jimnastik, sanal gerçeklik uygulamaları,

Kas kuvvetlendirme egzersizleri: Bir yere tırmanma aktiviteleri, ağırlık kaldırma, dirençli egzersizler,

Kemik kuvvetlendirme egzersizleri: Haftada en az 3 kez ip atlama, tırmanma, yürüyüş, basketbol, voleybol oyunları,

Esneklik egzersizleri: Yoga, pilates, dans

şeklinde siralanabilir[23].

\subsubsection{Aerobik egzersiz}

Aerobik egzersiz, gövde ve ekstremitelerdeki büyük kas gruplarını içeren, tüm vücudun çalıştığ 1 bir egzersiz çeşididir. Tempolu yürüyüş, yüzme, koşu, kayak, bisiklete binme, aktif video oyunları, tırmanma, dans, takım sporları, sıçrama ve atlama aktiviteleri aerobik egzersize örnek verilebilir[24,25]. Haftada en az üç gün ve $60 \mathrm{dk}$ yapılması önerilmektedir[20]. Ortalama 12 hafta boyunca haftada beş gün uygulanan aerobik egzersiz şiddeti, her dört haftada bir kalp hızı \%40'tan \%70'e çıkacak şekilde artırıldığında yağ oranı, kilo ve bel çevresi ölçümünde azalma, vücut kompozisyonunda olumlu gelişmeler olduğu gösterilmiştir[26]. Diyetle birlikte yapılan orta şiddetli aerobik egzersiz, kilo kaybını kolaylaştırmaktadır. Ancak diyet, kilo kaybı sırasında yağ dokusu ile birlikte yağsız vücut kütlesinde de azalmaya neden olurken, aerobik egzersiz yağsız vücut kütlesinin korunarak kilo kaybedilmesini sağlamaktadır[23].

Çocuklarda fiziksel aktivitenin azalmasıyla, aşırı kilo veya obezite ihtimali daha da artmaktadır. Kilo artışı ve sedanter hayatın önüne geçebilmek için özellikle genç popülasyon açısından, farklı alternatif fiziksel aktivite şekillerinin irdelenmesi gerekmektedir[20].

5.1.2 Yüksek Yoğunluklu Aralıklı Eğitim (High Intensity Interval Training-HIIT)

HIIT eğitimler yüksek yoğunluklu egzersiz ile kısa dinlenme periyotlarını birlikte içeren \%80-95 aralığında maksimum efor sarfedilen bir egzersiz stratejisidir. Maksimal yüklenme şiddeti, maksimum yüklenme süresi, dinlenme türü, toparlanma süresi ve toplam egzersiz süresi HIIT eğitimlerin temel komponentleridir[27]. Kısa sürede, verimli sonuçlar alınan HIIT eğitimlerin metabolik fonksiyonları, aerobik ve anaerobik kapasiteyi geliştirdiği bilinmektedir[28].

HIIT eğitimleri haftada iki-üç gün uygulanabilir ve max kalp hızı ya da maxVO $\mathrm{VO}_{2}$ nin \%80-\%100'üne, max aerobik hızın \%100'üne ulaşılması hedeflenir[29,30]. Beş sn-8 dk süresince aerobik egzersiz yapılır. Antrenman 20 sn egzersiz-10 sn toparlanma, 45 sn egzersiz-15sn dinlenme periyotları şeklinde toparlanma ve düşük yoğunluklu aerobik egzersiz uygulamaları ile yapilabilmektedir. Antrenmanın egzersiz ve dinlenme periyotları ile birlikte en fazla 20 dk sürmesi önerilmektedir[29,31,32]. Isınma egzersizlerinden sonra dizler üzerinde şınav, squat, burpees, mekik, step up (basamak egzersizi), jumping jack, ip atlama ve plank egzersizleri yapılmaktadır. Egzersizden sıkılmayı önlemek amacıyla 2 hafta ya da bir ay sonrasında benzer kas gruplarını çalıştıran egzersizler değiştirilerek uygulanabilir[33].

Son yıllarda yapılan çalıșmalarda düșük yoğunluklu programlara kıyasla egzersiz yapmak için gereken süreyi kısaltan yüksek yoğunluklu egzersiz programları ele alınmıştır. Beden eğitimi derslerinde geleneksel 10 dk'llk isınma periyotlarını HIIT protokolü ile değiştirmenin, beceri geliştirme, motor davranış ve esneklik gibi diğer fiziksel performansları iyileştirmek için zamanı kullanım açısından daha verimli olduğu söylenmektedir[34]. Bir HIIT protokolü, standart bir endurans eğitimine kıyasla $\% 70$ daha az zaman gerektirirken, orta yoğunlukta fiziksel aktiviteye benzer faydalar sağlar[34]. Yapılan çalışmalarda 6-12 haftalık HIIT programlarının obez çocuklarda kardiyorespiratuar sistemlerinde gelişme sağladığı, kas kan akışında iyileşme, BKİ'de azalma, kilo kayb1 ve visseral yağ düzenlenmesine katk1 sağladığı bulunmuştur[35].

\subsubsection{Yoga}

Çocuklar için çeşitli fiziksel aktiviteler olsa da yoga, sadece fiziksel sağlığa değil aynı zamanda psikososyal iyilik haline de faydalı olduğundan harika bir egzersiz sistemi olarak düşünülür(36). Temelinde yer alan 
asanalar (duruşlar), pranayama (nefes kontrolü) ve dhyana (meditasyon) ile uygulama sırasında çocuğun sadece kendisine konsantre olmasını sağlamaktadır. Ortalama 12 hafta boyunca, haftada en az iki seans ve $30 \mathrm{dk}$ yapılan yoga uygulamalarının beden farkındalığını, fiziksel uygunluğu geliştirdiği ve kilo kaybına yardımcı olduğu bulunmuştur[37,38].

Rutinde uygulanan egzersiz reçeteleri obezitesi olan çocuklar ve ergenlerde anormal biyomekanik stres oluşturabileceği düşüncesiyle bir endişe oluşturmaktadır. $\mathrm{Bu}$ endișe yürümeyle bile meydana gelen, tekrarlayan yüksek stresler nedeniyle eklemlerde dejenerasyon oluşması riskinden kaynaklanmaktadır[13]. Obezite ile ilişkili biyomekaniksel değişiklikler, gelişim süresince devam ederse kas-iskelet sistemi ve eklem sağlı̆̆ üzerinde kalıcı ve olumsuz etkiler birakabilir. Bunun önlenebilmesi için en erken dönemde müdahale edilmelidir.

Ergenlik döneminde, fiziksel aktivitenin tek başına obezitenin sebeplerini ortadan kaldırması pek de mümkün değildir. Çünkü fiziksel aktivite eksikliği, genetik, hareketsiz yaşam gibi durumların yanısıra benlik saygısının düşük olması, başarı kaygısı, depresyon gibi psikolojik sebepler de azımsanamayacak kadar fazladır[10]. Yoganın geleneksel amaçları vücut ile zihni birleştirmek, alışkanlıklar ve biliş üzerinde etki oluşturmak, mutluluk ve iyilik halini sağlamaktır[10,36]. Yogada gerekli olan denge, esneme ve bükülme hareketleri ile vücudun güçlenmesi ve esnekliğin artırılması yoganın fiziksel faydaları olarak sayılabilir. Aşırı kilolu ve obez çocuklarla yapılan çalışmalarda yoganın vücut ağırlığı, karın ve kalça çevresi genişliği, BKI'de iyileşme sağladığı ancak anlamlı olmadığ gösterilmiştir[10,36]. Yoganın yürüyüş üzerindeki etkilerinin incelendiği başka bir çalışmada ise, yürüyüşün geliştiği, ambulasyon sırasında özellikle kalça ve diz eklemlerinde meydana gelen uyumsuzluğun azaldığı, kalça fleksör ve addüktör kas kuvvetinin arttığ1 görülmüştür[13]. Fiziksel özelliklerin değerlendirildiği ve antropometrik ölçümlerin yapıldığı bir çalışmada yoganın gövde, kalça ve bacak bölgesindeki yağlanmayı azalttığı ve kilo kaybetmede etkili olduğu gösterilmiştir[10].

\subsubsection{Pilates}

Aşırı kilolu ve obez çocuklar için fiziksel aktiviteyi artırmaya yönelik yenilikçi yollar bulmaya ihtiyaç vardır[39]. Dikkatlerini çekmek, egzersize katılımlarını sürekli hale getirmek için farklı egzersiz tipleri denenebilir. Bunlardan biri de pilatestir. Pilates fiziksel ve zihinsel durumu geliştirmeyi amaçlayan, vücudun kor kaslarını hedefleyen, düşük etkili kasılmalar oluşturan egzersiz dizisidir[39,40]. Kas gücü ve kor stabilitenin artırılmasını sağlar, postural kontrol, dinamik denge, kas enduransı ve esnekliğin iyileştirilmesine katkıda bulunur. Pilates, tipik bir aerobik egzersiz değildir[41]. Genel prensiplerinde odaklanma, konsantrasyon, kontrol, dikkat ve nefes vardır[40]. Ancak diğer egzersiz modelleri gibi enerji tüketimini artırır ve hücresel metabolizmayı değiştirir. $\mathrm{Bu}$ etkileri ile pilatesin vücut kompozisyonu ve fiziksel performans seviyesi üzerindeki olumlu etkileri sağlıklı bireylerde kanıtlanmıştır[41].

Pilates, çocuklar için haftada 2-5 gün, 30-60 dk boyunca yapılabilir. Çocukların fiziksel fonksiyonları üzerindeki etkilerinin incelendiği çalıșmalarda 4 haftadan 3 aya kadar uygulanan pilatesin esnekliği artırdığı, kas gücü ve hareket hızını geliştirdiği, postural uyum ve dengeyi artırdığ düzgünlüğünü sağladığı, ağrıyı azalttığı sonucuna varılmıştır[40,42].

Tip 1 diyabeti olan çocuklarla yapılan bir çalışmada, pilates egzersizlerinin metabolik değerlerden trigliserit, toplam kolesterol, LDL düzeyinde bir değişiklik yapmazken HDL düzeyini artırdığı gözlenmiş, fiziksel performans parametrelerinden maksimum gücü, ortalama gücü, esnekliği ve dikey zıplama yüksekliğini önemli derecede artırdığ bulunmuştur[41].

\subsubsection{Sanal Gerçeklik Uygulamaları}

Aşırı kilolu veya obez çocuklar, normal kilodaki yaşıtlarına göre daha az aktiflerdir. Bu durum, boş zaman aktivitelerinin artık ekran temelli olması ve park gibi geleneksel çocuk oyun alanlarının kısıtlanmasından kaynaklanmaktadır. Obez çocukların sadece bu zorlukları değil, psikolojik ve fizyolojik engelleri de aşmaları gerekmektedir. Video oyun temelli uygulamalarla bu sorunları aşmaları mümkün olabilmektedir[43].

Sanal gerçeklik uygulamaları, sedanter ve obez çocuklarda fiziksel aktiviteye teşvik eden, özellikle egzersize motivasyonu artıran bir yöntemdir[44]. Sanal dünyada görsel bilgiyi motor davranışa dönüştürerek, standart şekillendirilmiş antrenmanların aksine, daha doğal ve gerçek dünyadaki aktivitelere benzer şekilde motor becerilerin geliştirilmesine katkı sağlar[45]. Çocukların nöromuskuler gelişimine yardımcı olan bu uygulama ile çocuk uygun eğitim yaşına ulaştığında sanal ortam dışında gerçekleştirilen daha karmaşı 1 eğitim ve antrenmanlara daha kolay adapte olabilir[45].

Yapılan çalışmalarda sanal gerçeklik uygulamasına katılan obez çocukların beklenti ve memnuniyetlerinin önemli derecede arttı̆̆ 1 , egzersiz sırasında bedenleri ile ilgili hissettikleri olumsuz düşüncelerin video oyun sırasında oluşmadığı ve dikkatlerini vücutlarından daha çok dış dünyaya verdikleri görülmüştür[43]. Egzersiz odaklı geçirilen sürenin artması ve oksijen tüketimin daha düzenli olması, sanal gerçeklik uygulamalarının fiziksel aktiviteyi artırmada oldukça verimli olduğunu göstermektedir[44].

\section{Sonuc}

Obeziteyi önlemeye yönelik çalışmalar multidisipliner yaklaşımla mümkün olmaktadır. Aşırı kilolu veya obez çocuklar için uygun diyet programı hazırlanmalı, bir fizyoterapist eşliğinde yaşına uygun egzersiz programı çizilmelidir. Çocuğun ilgisini çekecek, sıkılmadan devam edebileceği egzersiz çalışmaları 
yaptırmak hem çocuğun aktiviteye katılımını artırmaktadır hem de motivasyonunu yükselterek egzersiz süresini uzatmaktadır. Aile destekli egzersiz alışkanlığının kazandırılması, okulda beden eğitimi derslerinde yapılan farklı egzersizler fiziksel aktiviteyi artırarak obezitenin önlenmesinde büyük rol oynamaktadır[12].

\section{Referanslar}

1. Sevinç, Ö, Bozkurt, A.I, Gündoğdu, M, Baş Aslan, Ü, Ağbuğa, B, Aslan, Ş, ve ark. Evaluation of the effectiveness of an intervention program on preventing childhood obesity in Denizli, Turkey. Turkish Journal of Medical Sciences. 2011, 41(6), $1097-$ 105.

2.Kaya, M, Sayan, A, Birinci, M, Yildiz, M, Türkmen, K, The obesity prevalence among students between the ages of 5 and 19 in Kütahya, Turkish Journal of Medical Sciences, 2014, 44(1), $10-5$.

3. Gilman, A.D, Volpe, S.L, The global status of physical activity in the prevention oh childhood obesity, Pensar en Movimiento: Revista de ciencias del ejercicio y la salud, 2018, $16(2), 2$.

4. Yılmazbaş, P, Gökçay, G, Çocukluk çağı obezitesi ve önlenmesi, Çocuk Dergisi, 2018, 18.3, 103-112.

5.Berberoğlu, M, Adolesanlarda obezite, IÜ Cerrahpaşa Tıp Fakültesi Sürekli Tıp Eğitimi Etkinlikleri Sempozyum Dizisi, 2008, Adolesan S(63), 79-80.

6. Ökdemir, D, Esen, İ, Çocukluk çağı obezitesinden korunma ve tedavi yaklaşımları, Firat Tip Dergisi,2018, 23, 100-5.

7.Erdim, L, Kuğuoğlu, S, Fazla kilolu çocuklara yönelik beslenme ve egzersiz programının etkisi, Doktora tezi, 2012.

8. Köksal, G, Özel, H.G, Okul öncesi dönemde obezite. Ankara: TC Sağlık Bakanlığı Temel Sağlık Hizmetleri Genel Müdürlüğü Beslenme ve Fiziksel Aktiviteler Daire Başkanlığı Yayınları, 2008.

9. Kumar, S, Kelly, A.S, Review of childhood obesity: From epidemiology, etiology, and comorbidities to clinical assessment and treatment, Mayo Clinic Proceedeings, 2017, 92(2), 251-65.

10. Rathi, S.S, Joshi, R.R, Tekur, P, et al., Effect of the yoga on anthropometric and physical assessments in adolescent obesity, Endocrinology and Metabolic Syndrome, 2018,07(05).

11. Yıldı, D, Fidancı, B.E, Suluhan, D, Cocukluk dönemi obezitesi ve önleme yaklaşımları, TAF Preventive Medicine Bulletin, 2015, 14(4), 338-45.

12. Tarakc1, E, Ersöz Hüseyinsinoğlu, B, Çiçek, A, Physical inactivity, obesity and preventive rehabilitation approaches in children: Review, Turkiye Klin ikleri Journal of Health Science, 2016, 1(2), 111-8.

13. Hainsworth, K, Liu, X, Simpson, P, Swartz, A, Linneman, N, Tran, S, et al., A Pilot study of Iyengar yoga for pediatric obesity: Effects on gait and emotional functioning, Children, 2018, 5(7), 92.

14. Inal, S, Canbulat, N, Çocukluk çağı obezitesine genel bakış, Güncel Pediatri, 2013, 11(1), 27-30.

15. Lee, E.Y, Yoon, K.H, Epidemic obesity in children and adolescents: risk factors and prevention, Frontiers in Medicine, 2018,12(6),658-66.

16. Firouzi, S, Koon, B, Noor, M, Sadeghilar, A, Sleep habits, food intake, and physical activity levels in normal and overweight and obese Malaysian children, Obesity Research \& Clinical Practice, 2014, 8, e70-8.

17. Nixon, G.M, Thompson, J.M.D, Han, D.Y, Becroft, D.M, Clark, P.M, Robinson, E, et al., Short sleep duration in middle childhood: Risk factors and consequences, Sleep, 2008, 31(1), $71-8$.

18. Fatima, Y, Doi, S.A.R, Mamun, A.A, Sleep quality and obesity in young subjects : a meta-analysis, Obesity Reviews, 2016, 17(11), 1154-66.

19. U.S. Department of Health and Human Services, Physical Activity Guidelines for Americans, 2.edition, 2018.

20. García-Hermoso, A, Cerrillo-Urbina, A.J, Herrera-Valenzuela, T, Cristi-Montero, C, Saavedra, J.M, Martínez-Vizcaíno, V, Is highintensity interval training more effective on improving cardiometabolic risk and aerobic capacity than other forms of exercise in overweight and obese youth? A meta-analysis, Obesity Reviews, 2016, 17(6), 531-40.

21. Liu, J, Zhu, L, Su, Y, Comparative effectiveness of high-intensity interval training and moderate-intensity continuous training for cardiometabolic risk factors and cardiorespiratory fitness in childhood obesity: A meta-analysis of randomized controlled trials, Frontiers in Physiology, 2020, 11(April), 1-18.

22. WHO, Global Recommendations on Physical Activity for Health, In: World Health Organization: Geneva, 2010.

23. Bülbül, S, Çocuklarda obezite tedavisinde egzersiz, Türk Peidatri Arșivi, 2020, 55(1), 2-10.

24. Sekhon, B.S, Maniazhagu, D, Effects of aerobic trainıng and jump rope training on flexibility of overweight children, Journal of Emerging Technologies and Innovative Research, 2018, 5(5), 385-9.

25. Kelley, G.A, Kelley, K.S, Pate, R.R, Exercise and BMI z-score in overweight and obese children and adolescents: a systematic review and network meta-analysis of randomized trials, Journal of Evidence Based Medicine, 2017, 10(2), 108-28.

26. Bharath, L.P, Choi, W.W, Cho, J, min, Skobodzinski, A.A, Wong, A, Sweeney, T.E, et al. Combined resistance and aerobic exercise training reduces insulin resistance and central adiposity in adolescent girls who are obese: randomized clinical trial, European Journal of Applied Physiology, 2018, 118, 1653-60.

27. Azuma, K, Matsumoto, H, Potential universal application of highintensity interval training from athletes and sports lovers to patients, Keio Journal Of Medicine, 2017, 66(2), 19-24.

28. Akgül, Ş.M, Koz, M, Gürses, V.V, Kürkçü, R, Yüksek şiddetli interval antrenman, Spormetre, 2017, 15(2), 39-46.

29. Liu, J.X, Zhu, L, Deng, J.M, The effects of high-intensity interval training versus moderate-intensity continuous training on fat loss and cardiometabolic health in pediatric obesity: A protocol of systematic review and meta-analysis, Medicine, 2019, 98(10), e14751.

30. Eddolls, W.T.B, McNarry, M.A, Stratton, G, Winn, C.O.N, Mackintosh, K.A, High-intensity interval training interventions in children and adolescents: a systematic review, Sports Medicine, 2017, 47, 2363-74.

31. Kravitz, L, Zuhl, M, High intensity interval training vs continuous cardio training: Battle of the Aerobic Titans, 2014.

32. Bilge, M, Yıldırım, D.S, Ersöz, G, Güncel yüksek şiddetli aralıkl antrenman (high intensity interval training- hitt) uygulamalarının kardiyovasküler- metabolik ve performans yantları: sistematik derleme, Turkiye Klinikleri Journal of Sports Science, 2021;

33. Bogataj, Š, Trajković, N, Cadenas-Sanchez, C, Sember, V, Effects of school-based exercise and nutrition intervention on body composition and physical fitness in overweight adolescent girls, Nutrients, 2021, 13(1), 1-12.

34. Chandler, R.M, Stringer, A.J, A comprehensive exploration into utilizing high-intensity interval training (hut) in physical education classes, Journal of Physical Education, Recreation \& Dance. 2020, 91(1), 14-23.

35. Cvetković, N, Stojanović, E, Stojiljković, N, Nikolić, D, Milanović, Z, Effects of a 12 week recreational football and highintensity interval training on physical fitness in overweight children, Facta Universitatis Series Physical Education and Sport, 2018, 16(2), 435.

36. Kim, K.J, Wee, S.J, Gilbert, B.B, Choi, J, Young children's physical and psychological well-being through yoga, Childhood Education, 2016, 92(6), 437-45.

37. Nanthakumar, C, The benefits of yoga in children, Journal of Integrative Medicine, 2018, 16(1), 14-9.

38. Dai, C.L, Sharma, M, Chen, C.C, Yesilyurt, E, Godbey, S, Yoga as an alternative therapy for weight management in child and adolescent obesity: A systematic review and implications for research, Alternative Therapies In Health Medicine, 2021, 27(1), $48-55$.

39. Jago, R, Jonker, M.L, Missaghian, M, Baranowski, T, Effect of 4 weeks of pilates on the body composition of young girls, Preventive Medicine, 2006, 42(3), 177-80.

40. Hornsby, E, Johnston, L.M, Effect of pilates intervention on physical function of children and youth: A systematic review, Archives of Physical Medicine and Rehabilitation, 2020, 101(2), 317-28.

41. Tunar, M, Ozen, S, Goksen, D, Asar, G, Bediz, C.S, Darcan, S, The effects of pilates on metabolic control and physical 
performance in adolescents with type 1 diabetes mellitus, Journal of Diabetes Complications, 2012, 26(4), 348-51.

42. Hartono, G.E, Kesoema, T.A, A.P RI, Anantyo, D.T, The effect of mat pilates in lumbar flexibility of overweight and obese children, Diponegoro Medical Journal, 2020, 9(3), 220-4.

43. Cebolla, I, Martí, A, Álvarez-Pitti, J.C, Provinciale, J.G, Lisón, J.F, Rivera, R.B, Alternative options for prescribing physical activity among obese children and adolescents: brisk walking supported by an exergaming platform, Nutricion Hospitalaria, 2015, 31(2), 841-8.

44. Baños, R.M, Escobar, P, Cebolla, A, Guixeres, J, Alvarez Pitti, J, Lisón, J.F, et al., Using virtual reality to distract overweight children from bodily sensations during exercise, Cyberpsychology, Behavior and Social Networking, 2016, 19(2), 115-9.

45. Kiefer, A.W, Pincus, D, Richardson, M.J, Myer, G.D, Virtual reality as a training tool to treat physical inactivity in children, Frontiers in Public Health, 2017, 5, 349.

http://edergi.cbu.edu.tr/ojs/index.php/cbusbed isimli yazarın CBU-SBED başlıklı eseri bu Creative Commons Alınt1-Gayriticari4.0 Uluslararası Lisansı ile lisanslanmıştır.

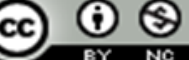

